\title{
Study of old ecological hazards, oil seeps and contaminations using earth observation methods - spectral library for oil seep
}

\author{
Eva Smejkalová*, Petr Bujok ${ }^{1}$, Miroslav Pikl² $^{2}$ \\ ${ }^{1}$ VŠB - Technical University of Ostrava, Czech Republic \\ Institute of Geological Engineering, Faculty of Mining and Geology \\ ${ }^{2}$ Academy of Sciences of the Czech Republic, Czech Republic \\ Global Change Research Centre, Department of Remote Sensing and Earth Observation \\ *Corresponding author's e-mail: evasmejkal@gmail.com
}

Keywords: remote sensing, oil contaminations, hydrocarbon seepage, spectral library, satellite.

\begin{abstract}
The possibilities of remote sensing techniques in the field of the Earth surface monitoring and protection specifically for the problems caused by petroleum contaminations, for the mapping of insufficiently plugged and abandoned old oil wells and for the analysis of onshore oil seeps are described. Explained is the methodology for analyzing and detection of potential hydrocarbon contaminations using the Earth observation in the area of interest in Slovakia (Korňa) and in Czech Republic (Nesyt), mainly building and calibrating the spectral library for oil seeps. The acquisition of the in-situ field data (ASD, Cropscan spectroradiometers) for this purpose, the successful building and verification of hydrocarbon spectral library, the application of hydrocarbon indexes and use of shift in red-edge part of electromagnetic spectra, the spectral analysis of input data are clarified in the paper. Described is approach which could innovate the routine methods for investigating the occurrence of hydrocarbons and can assist during the mapping and locating the potential oil seep sites. Important outcome is the successful establishment of a spectral library (database with calibration data) suitable for further application in data classification for identifying the occurrence of hydrocarbons.
\end{abstract}

\section{Introduction}

The near-surface hydrocarbon seeps range from large concentrations of visible hydrocarbons known as macroseeps to very subtle chemically detectable concentrations known as microseeps (Abrams et al. 2001). The hydrocarbon seepages and contaminations as the object of the following research can be observed on the surface in the form of the natural oil macroseepage (visible leak), in the form of leakage caused by human interventions which appears as an oil contamination or in the form of microseepage which is not visible but indirectly detectible due to occurring influence on the above soils and the vegetation. With reference to the Encyclopedia of Geology (Gluyas et al. 2005) the tertiary migration includes leakage, seepage, dissipation and alteration of petroleum as it reaches the Earth's surface. The products of seepage may be gas chimneys in the shallow sediment, gas hydrate layers and mounds, cemented pock marks and mud volcanoes, effects on vegetation, and live oil and gas seepage at the surface.

Back in the 1970s the Landsat satellite technology was applied in Anadarko Basin (Texas) for analyzing the hydrocarbons (Short 1998) and was utilized also for indirect mapping of hydrocarbons (Bentz 1975). According to the scientific work of the group of authors from the Faculty of
Geo-Information Science and Earth Observation (ITC), University of Twente, and their great long-time contribution to this scientific topic it is obvious that optical remote sensing is usable in the field of detecting the hydrocarbon seepages which occur on the surface, in the near surface and also offshore. In the regions of Czech Republic and Slovakia, which is the focus area of ongoing research, no study efforts using EO for analyzing the hydrocarbon seeps and contaminations have been conducted yet. The indirect mapping methods are often applied using the algorithms based on the searching of geological structures typical for the hydrocarbons (traps, faults, lineaments) or based on the analyzing the stressed vegetation. For the ongoing study important are the results of German research activities (Kühn et al. 2004) and the development of so-called hydrocarbon index and the definition of the hydrocarbon seepage spectral characteristics. Other researchers in the field of remote sensing are studying the geochemical changes (Rubio 2002) and the geochemistry for detection of the hydrocarbon microseepages (Khan et al. 2008). Except the academic research efforts very remarkable is the work of James Ellis in private domain and the activities of his Ellis GeoSpatial company (Ellis et al. 2001).

In the frame of introduction it has to be noted that the ongoing research is focused on using the optical multispectral and hyperspectral EO (Earth Observation) approach. The most 
important intervals of the electromagnetic spectra in which the absorbing bands of hydrocarbons are located (hydrocarbon feature) is the interval 2310-2350 nm (Qingjiu et al. 1992) and the interval of 1700-1750 nm (Horing et al. 2001). During the pilot case studies (Kuwait, California) the first tests and the usability of methods were evaluated (Smejkalova et al. 2012). Afterwards the activities were focused on the areas in Czech Republic, Slovakia, partly in California, and thus this article is describing the step forward to activities in Korňa and Nesyt.

The aim of the study is focused on the development of a procedure based on remote sensing technologies for the detection of probable occurrences of hydrocarbons, or the presence of possible contamination caused by hydrocarbon substances in the area of temperate Earth climate zone. One of the goals is to establish a database of reference spectra - spectral library for the hydrocarbon surfaces (areas with existing hydrocarbon seepages, contaminations, soil and vegetation in the close seepage vicinity). For the analytical part of the work it is essential to obtain suitable input data (in-situ and satellite). Calibration data will be acquired using spectroradiometrical measurements in the field near natural hydrocarbon seepage located in Korňa village (the Slovak Republic). Practical part contains satellite imagery pre-processing and field data processing.

\section{Methodology}

\section{Study area}

The first area of interest is placed in the northwest part of Slovakia in Korn̆a village $\left(49.4111^{\circ} \mathrm{N} 18.5796^{\circ} \mathrm{E}\right)$ where active natural oil macroseepage is located. Korňa and its broader surrounds are geologically part of the Magura Nappe of the Carpathian Flysch Belt. Seepage oil represents thermally mature light oil, which originated during the main phase of oil generation, accompanied by natural gas with a prevalence of methane. A small amount of this oil plus water seeped to the surface, carried by a natural gas lift. The area covered by seepage is 0,2 hectare and a small terrain depression occurs at this place. Water flows from this depression and an oil film of dark red to dark brown color is visible on the water surface. Bubbles of natural gas rise to this water surface in irregular intervals, and the water and oil drain to a narrow trench slope before disappearing underground approx. 50-60 meters further along (Milička et al. 2012). The exploitation works of the Carpathian Resources (exploration well Korňa 1, oil flowed from a $15 \mathrm{~m}$ interval, $178-193 \mathrm{~m}$ depth) demonstrated that the achievable long term flow rate from the Korňa well was too low to be economic (Carpathian Annual Report, 2003).

Another study area is the ancient oil and gas deposit Nesyt $\left(48.8305^{\circ} \mathrm{N} 17.0964^{\circ} \mathrm{E}\right)$ situated at the bottom of the old pond Nesytý which was changed to arable land in the $18^{\text {th }}$ century. The oil and gas exploration activities at Nesyt started in 1919 and until 1939 approx. 127,6 thousand tons of oil were drilled (Bednař́k ková et al. 1984). The exploitation was closed due to production drop and due to the possible environmental threats along the river Morava nearby.

The assumption is that in the Nesyt area the contaminations caused by badly p\&a (plugged and abandoned process) wells and the danger of bedrock, groundwater, agriculture soil and surrounding ecosystem contamination is still present. The studied zone of Nesyt area selected for this research covers the region of approximately 800 hectare. Initiating pilot study of the overall research methodology was performed using the satellite data from Kuwait area (Burgan oil field) and from Ventura Basin in California (Smejkalová et al. 2012). Afterwards the research activities are focused on Korňa and Nesyt sites (Fig. 1). It is necessary to mention that for the purpose of this ongoing research the field and airborne data from the Ventura Basin (Ojai town and Sulphur Mountain) were provided to authors by ITC. Due to this fact another region in focus is the hydrocarbon seepage area near Ojai town in California $\left(34.4292^{\circ} \mathrm{N} 119.1402^{\circ} \mathrm{W}\right)$.

\section{Input data (in-situ)}

For providing the in-situ ground truth values the Korňa natural oil seep was mapped. The initial field survey at Nesyt area and also at Korn̆a natural seep was performed with the Field Multispectral Radiometer Cropscan MSR16R type. The radiometer contains 16 sensors operating in the spectral range from 450 to $1750 \mathrm{~nm}$ (visible and near infrared region). At each sampling location the recorded spectra represent an average of 5 measurements. The usability of Cropscan for mapping hydrocarbon seepages is limited because it provides only 16 bands in the region up to $1750 \mathrm{~nm}$ and its primary purpose of use is agricultural research. The need of obtaining the in-situ spectra in narrower bands and in wavelengths longer than $1700 \mathrm{~nm}$ raised and because of the mentioned reasons the field survey continued with ASD Fieldspec 3 spectroradiometer.

The ASD Fieldspec survey was carried out in autumn (October) 2014 in Korňa village. The reflectance of 16 samples (14 contaminated and 2 uncontaminated soil samples) was measured in-situ with ASD FieldSpec 3 hi-Res Spectrometer (ASD Inc. USA) in spectral range 350-2500 nm and spectral resolution of $1 \mathrm{~nm}$. Overall 10 spectra were recorded at each sample location while each recorded spectrum represents average of 20 measurements. ASD contact probe equipped with halogen light source was used because of cloudy weather conditions and low sun elevation angle $(<15 \mathrm{deg})$. The white reference panel (standard) was measured to calibrate for reflectance before individual sample measurements. The optic of contact probe was cleaned after each sample measurement. The recorded data were preprocessed performing the dynamic parabolic correction (Beal et al. 2009) to remove the shifts (at

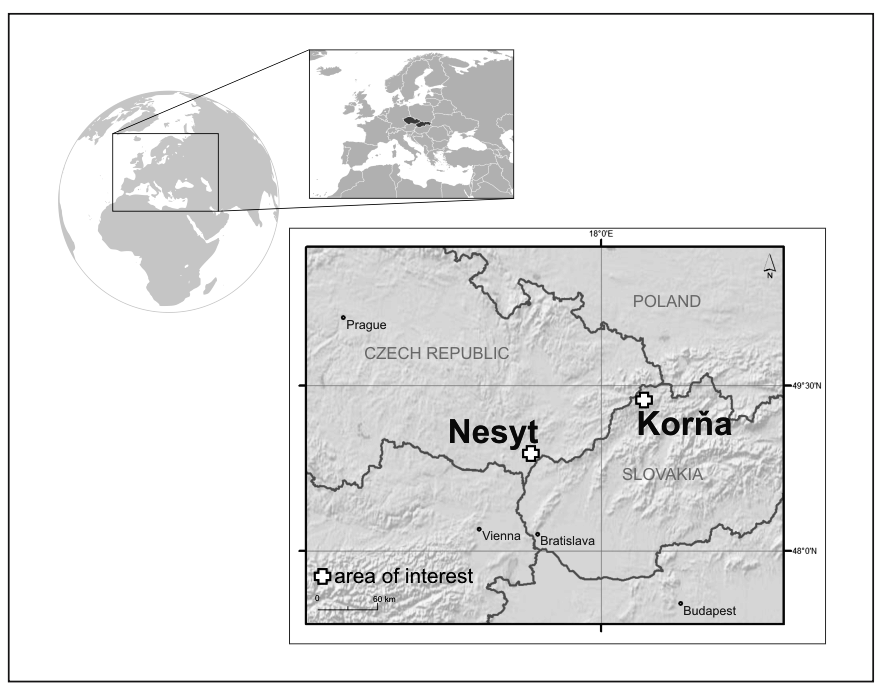

Fig. 1. Locations of study areas 
1000 and $1800 \mathrm{~nm}$ ) between the 3 spectrometers from which the instrument is composed.

In addition to in-situ data from Korňa and Nesyt area the processed data from field surveys in California with ASD were obtained from ITC and used in the frame of ongoing research.

\section{Input data (airborne, spaceborne)}

Except the field survey data another input for the study is spaceborne and airborne imagery (see Table 1). Depending on the EO data parameters crucial for studies of hydrocarbon seepage selected were data from scanner Hyperion, ALI (EO-1 satellite), scanner ASTER (Terra satellite) and Landsat satellite. From ITC the airborne data from AVIRIS and HyMap (Probe-1) sensor were obtained.

In most of the already accomplished researches the airborne hyperspectral data were applied for the oil seepage analysis. There is lack of hyperspectral spaceborne data acquired in SWIR (short wave infrared part of EM spectra) (shore wave infrared interval) and the only running spaceborne mission is Hyperion sensor (EO-1 satellite). The sensor ASTER since 2008 has problems with SWIR detector and SWIR data acquired after April 2008 are not usable. There are several missions preparing to launch (PRISMA, EnMAP) but for instance the launching of German EnMAP satellite with planned spectral range 420-2450 nm very suitable for hydrocarbon prospecting applications is delayed and postponed to the end of 2018. Until now for our study there is no direct coverage of Korňa area and of Nesyt area with the Hyperion data. The data acquisition request for Korňa area is pending and the Hyperion data covering the southern part from Nesyt area are available. In this area (Gbely - Slovakia) the analogous oil and gas exploitation activities as in Nesyt area were present. Therefore, the access to the most appropriate data is limited.

\section{Methodological outline}

Described are methods and algorithms used for the purpose of this study.

\section{Building the spectral library}

Part of EO algorithms suitable for analyzing the hydrocarbon contaminations need to work with so-called spectral endmembers on their input. It is crucial to have the spectrally "pure" features (spectral endmembers) corresponding to the analyzed material (hydrocarbon seepage). The source for definition of spectral endmembers could be the spectral library.

After conduction of field measurements by using the Cropscan and the ASD the spectral reflectance curves need to be processed, analyzed and interpreted. For this purpose the processing tool for building the spectral libraries is utilized. During the building of spectral library the data need to be cleaned from the white standard captures, the detector steps have to be removed and each sample has to be evaluated, for instance, using the photographs from the field measurements and the detailed description of each sample created during the field survey.

The accuracy of the created spectral library could be evaluated with standard spectral library. For this purpose it is possible to use the methods for rank the match of unknown spectra with spectral library. The techniques such as Binary Encoding, Spectral Angle Mapper and Spectral Feature Fitting are utilized for this purpose. The results of the match are from 0 to 1 , whereby the 1 shows perfect match. The binary encoding (BE) method encodes the unknown spectra data and standard library spectra into zero and one, based on whether a band falls below or above the spectra mean. The spectral angle mapper (SAM) uses an n-D angle to match unknown data to reference standard spectra. The spectral feature fitting (SFF) calculates a least-squares-fit between each reference and the unknown spectra (Exelis 2014).

\section{Computation of band ratios (HD, HI, RE)}

EO methods in geological applications utilize the band ratios and computations of indexes and in our research the hydrocarbon detection (HD), the hydrocarbon index (HI) and index describing shift in the Red-Edge (RE) of contaminated (stressed) vegetation were chosen.

The vegetation located along the petroleum pipelines was studied with HyMap and ASTER sensor data in research of ITC (Noomen 2007). This type of vegetation could be influenced (stressed) by leakage from the pipeline. One of the typical spectral characteristic of stressed vegetation is the shift of Red-Edge position. The Red-Edge is the name given

Table 1. Summary of airborne and spaceborne data applied for the study

\begin{tabular}{|c|c|c|c|c|c|c|}
\hline attribute & HYPERION & ALI & ASTER & LANDSAT & AVIRIS & HyMap \\
\hline Sensor type & $\begin{array}{l}\text { Spaceborne } \\
\text { hyperspectral }\end{array}$ & $\begin{array}{l}\text { Spaceborne } \\
\text { multispectral }\end{array}$ & $\begin{array}{l}\text { Spaceborne } \\
\text { multispectral }\end{array}$ & $\begin{array}{l}\text { Spaceborne } \\
\text { multispectral }\end{array}$ & $\begin{array}{c}\text { Airborne } \\
\text { hyperspectral }\end{array}$ & $\begin{array}{c}\text { Airborne } \\
\text { hyperspectral }\end{array}$ \\
\hline No. of bands & 242 & 7 & 15 & 8 & 224 & 128 \\
\hline $\begin{array}{c}\text { Bands for } \\
\text { "hydrocarbon" }\end{array}$ & $\begin{array}{l}155-160 \\
216-220\end{array}$ & $\begin{array}{l}5 \\
7\end{array}$ & $\begin{array}{l}4 \\
8\end{array}$ & $\begin{array}{l}5 \\
7\end{array}$ & $\begin{array}{l}142-147 \\
204-205\end{array}$ & $\begin{array}{c}83-87 \\
111-113\end{array}$ \\
\hline $\begin{array}{l}\text { Spectral } \\
\text { resolution }\end{array}$ & $426-2395 \mathrm{~nm}$ & $433-2350 \mathrm{~nm}$ & $500-2500 \mathrm{~nm}$ & $441-2345 \mathrm{~nm}$ & $380-2500 \mathrm{~nm}$ & $45-2500 \mathrm{~nm}$ \\
\hline Spatial resolution & $30 \mathrm{~m}$ & $30 \mathrm{~m}$ & $\begin{array}{l}15 \mathrm{~m} \text { (VNIR) } \\
30 \mathrm{~m} \text { (SWIR) }\end{array}$ & $30 \mathrm{~m}$ & $20 \mathrm{~m}$ & $8 \mathrm{~m}$ \\
\hline $\begin{array}{l}\text { Study area } \\
\text { coverage }\end{array}$ & $\begin{array}{c}- \\
\text { NESYT } \\
\text { OJAI }\end{array}$ & $\begin{array}{c}\text { KORŇA } \\
\text { NESYT } \\
\text { OJAI }\end{array}$ & $\begin{array}{c}\text { KORŇA } \\
\text { NESYT } \\
\text { OJAI }\end{array}$ & $\begin{array}{c}\text { KORŇA } \\
\text { NESYT } \\
\text { OJAI }\end{array}$ & $\begin{array}{c}- \\
- \\
\text { OJAI }\end{array}$ & $\begin{array}{c}- \\
- \\
\text { OJAI }\end{array}$ \\
\hline
\end{tabular}


to the abrupt reflectance change in the $680-740 \mathrm{~nm}$ regions of vegetation spectra that is caused by the combined effects of strong chlorophyll absorption and leaf internal scattering (Dawson et al. 1998). According to previous research (Noomen 2007) the spectral characteristics of stressed and contaminated vegetation and their Red-Edge position shifts towards shorter or longer (UV or IR) wavelengths. Noomen was testing a great number of indexes calculating the shifts in Red-Edge and preferred the method developed by Guyot and Baret (Noomen 2007) and calculation of Red-Edge position (REP). This method contains a two-step calculation ( $\mathrm{R}$ means reflectance at wavelength):

$$
R i=\frac{R_{670}+R_{780}}{2} \quad R E P=700+40 *\left[\frac{R_{i}-R_{700}}{R_{740}-R_{700}}\right]
$$

In the area of the petroleum contamination detection two principal approaches to band ratios computations were studied: hydrocarbon detection (HD) and computation of hydrocarbon index (HI). Using airborne hyperspectral sensors data acquired from known hydrocarbon leaks have found that an absorption feature near $2.31 \mu \mathrm{m}$ is very sensitive to the amount of a specific component of the hydrocarbons (Short 1998).

The hydrocarbon detection (HD) means two reflectance values divided by the value of the decreased reflectance in the spectral curve.

The applied formula is:

$$
H D=\frac{A+C}{2 B}
$$

where, if $\mathrm{HD}>1$ the indices of hydrocarbons are detected (A band $=2297 \mathrm{~nm}, \mathrm{~B}$ band $=2313 \mathrm{~nm}, \mathrm{C}$ band $=2329 \mathrm{~nm}$ ) (Short 1998).

Hydrocarbon index (HI) was defined in the German research (Kühn et al. 2004) and applied using the digital images acquired during airborne data acquisition of hyperspectral HyMap scanner (Fig. 2).

The hydrocarbon spectral features were observed in the interval of electromagnetic spectra of approximately $1730 \mathrm{~nm}$. The hydrocarbon index uses the vertical line $\mathrm{HI}=\mathrm{BB}^{\prime}$ to confirm the presence (indices) of hydrocarbon substances. If the petroleum affected or contaminated surfaces are present in the surveyed area, the index points $\mathrm{A}, \mathrm{B}$ and $\mathrm{C}$ form a triangle and the $\mathrm{HI}>0$ (see Fig. 2). There is a direct proportion between $\mathrm{HI}$ and the quantity of petroleum substances. The hydrocarbon index is calculated upon the following formula (Kühn et al. 2004):

$$
H I=\left(\lambda_{A}-\lambda_{B}\right) \cdot \frac{R_{C}-R_{A}}{\lambda_{C}-\lambda_{A}}+R_{A}-R_{B}
$$

$R_{A}, R_{B}$ and $R_{C}$ are the values of spectral reflectance on the wavelengths $\lambda_{A}, \lambda_{B}$ and $\lambda_{C}$. As $A$ band the wavelength $1705 \mathrm{~nm}$, as B $1729 \mathrm{~nm}$ and as C band $1741 \mathrm{~nm}$ were set.

\section{Spectra based classification}

For every mineral, rock or the occurrence of chemical change on the surface it is important to analyze only narrow intervals of electromagnetic spectra. The aim is to search the typical shapes of curves in the selected intervals and determine the absorption bands (maximums or minimums in absorption).

For classification it is possible to use the approaches of minimum distance classificator (MDC) which uses the mean vectors of each spectral endmember and calculates the Euclidean distance from each unknown pixel to the mean vector for each class (Exelis 2014). Another possibility is to use spectral angle mapper (SAM) approach which uses an n-D angle to match pixels to reference spectra (Exelis 2014).

Overview of data inputs, areas of interest and methods applied is listed in Table 2 .

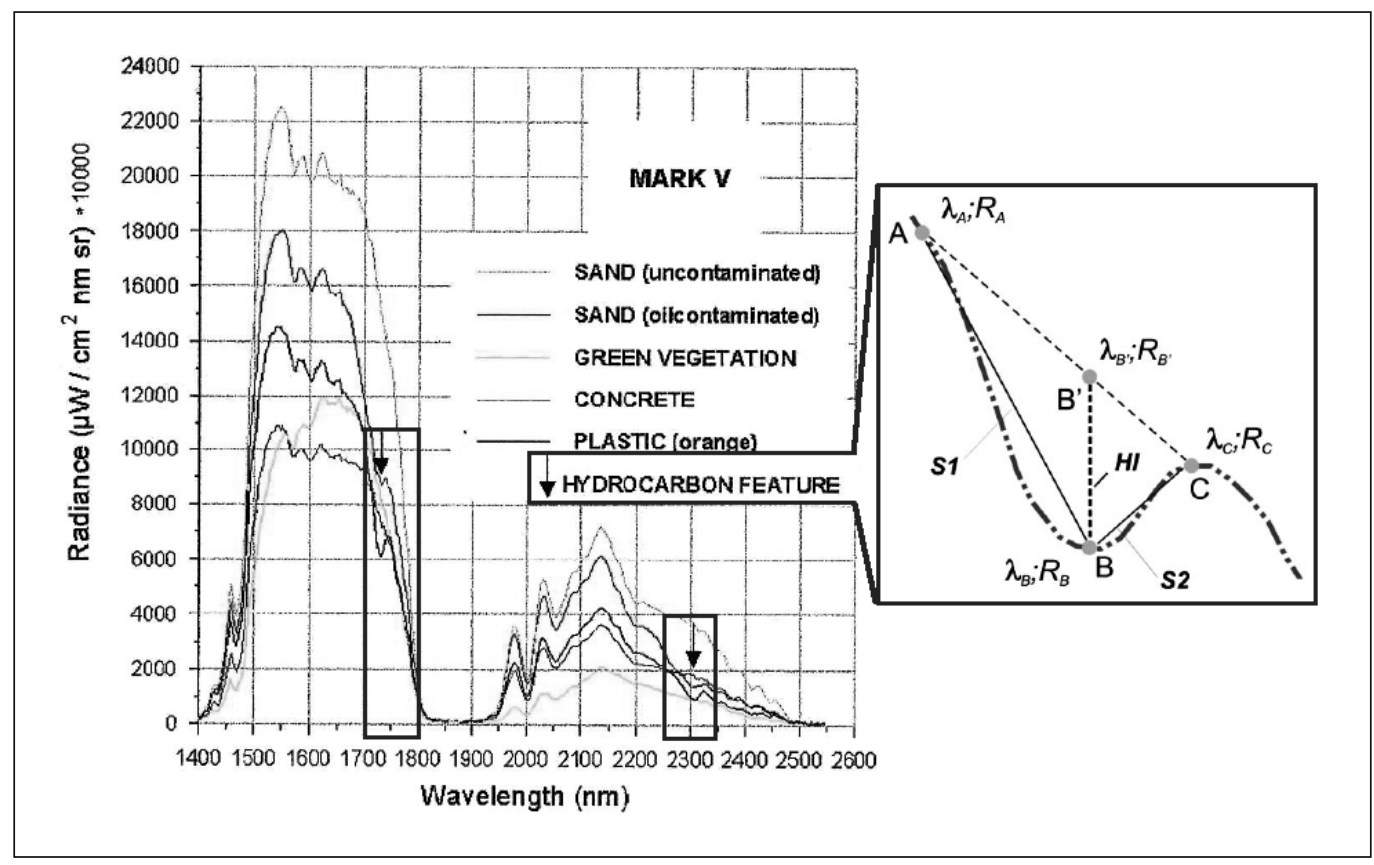

Fig. 2. Hydrocarbon feature and hydrocarbon index (Kühn et al. 2004) 


\section{Results and discussion}

Described and discussed is building and establishing the spectral library based on in-situ data. Afterwards two types of existing approaches were evaluated - on the one hand, computation of band ratios (indexes) such as HD, HI, RE and, on the other hand, the analyses using the spectral characteristics.

\section{Spectral library}

After successful building of spectral library for Korňa natural hydrocarbon seepage the accuracy of spectral library was evaluated. The results in comparing the built spectral library (SL) with ASD Fieldspec 3 input data from Korňa and standard data from California (ITC) showed the correspondence (see Figure 3):
- spectra sample no. 70 and no. 123 taken in Korňa from the area of seepage (solid line)

- SMR Oil spectra taken in the lab from the oil liquid and streaming downhill found at the bottom of Sulphur Mountain California (dashed line)

Another comparison is presented in Figure 4 below:

- spectra sample no.180 and no.123 taken in Korňa from the surroundings of the seepage area where the land was covered by bare soil (solid line)

- Ojai dead wood is field spectra taken from the dead plant materials and wood in the Californian seep surroundings (dashed line)

In Table 3 are presented the results from spectral matching method between standard spectral library built with data from California Ventura Basin hydrocarbon seepages (obtained from ITC) and spectral library created based on

Table 2. Summary of study areas, input data and methods of research

\begin{tabular}{|c|c|c|c|c|}
\hline Input data & $\begin{array}{l}\text { KORÑA } \\
\text { Slovakia }\end{array}$ & $\begin{array}{l}\text { NESYT } \\
\text { Czech Republic }\end{array}$ & \multicolumn{2}{|c|}{$\begin{array}{l}\text { OJAI } \\
\text { California }\end{array}$} \\
\hline Cropscan & data yr. 2010, yr. 2014 & data yr. 2010 & & - \\
\hline ASD & data yr. 2014 & - & data pro & vided by ITC \\
\hline Airborne & - & - & AVIRIS, H & yMAP (by ITC) \\
\hline Spaceborne & $\begin{array}{c}- \\
\text { Ali } \\
\text { ASTER } \\
\text { Landsat }\end{array}$ & $\begin{array}{c}\text { Hyperion (south from Nesyt) } \\
\text { Ali } \\
\text { ASTER } \\
\text { Landsat }\end{array}$ & & $\begin{array}{l}\text { perion } \\
\text { Ali } \\
\text { STER } \\
\text { andsat }\end{array}$ \\
\hline Spectral Library & \multicolumn{4}{|c|}{ Processing the field data, building the library, matching with standard library (methods SFF, BE, SAM) } \\
\hline HD, HI, RE & $H I=\frac{2}{3}\left(R_{1741}-R_{1705}\right)+R_{1705}-R_{1729}$ & $H D=\frac{R_{2297}+R_{2329}}{2 * R_{2313}}$ & $R E=700+40 *$ & $\frac{\frac{R_{670}+R_{780}}{2}-R_{700}}{R_{740}-R_{700}}$ \\
\hline Classification & \multicolumn{4}{|c|}{ MDC, SAM } \\
\hline
\end{tabular}

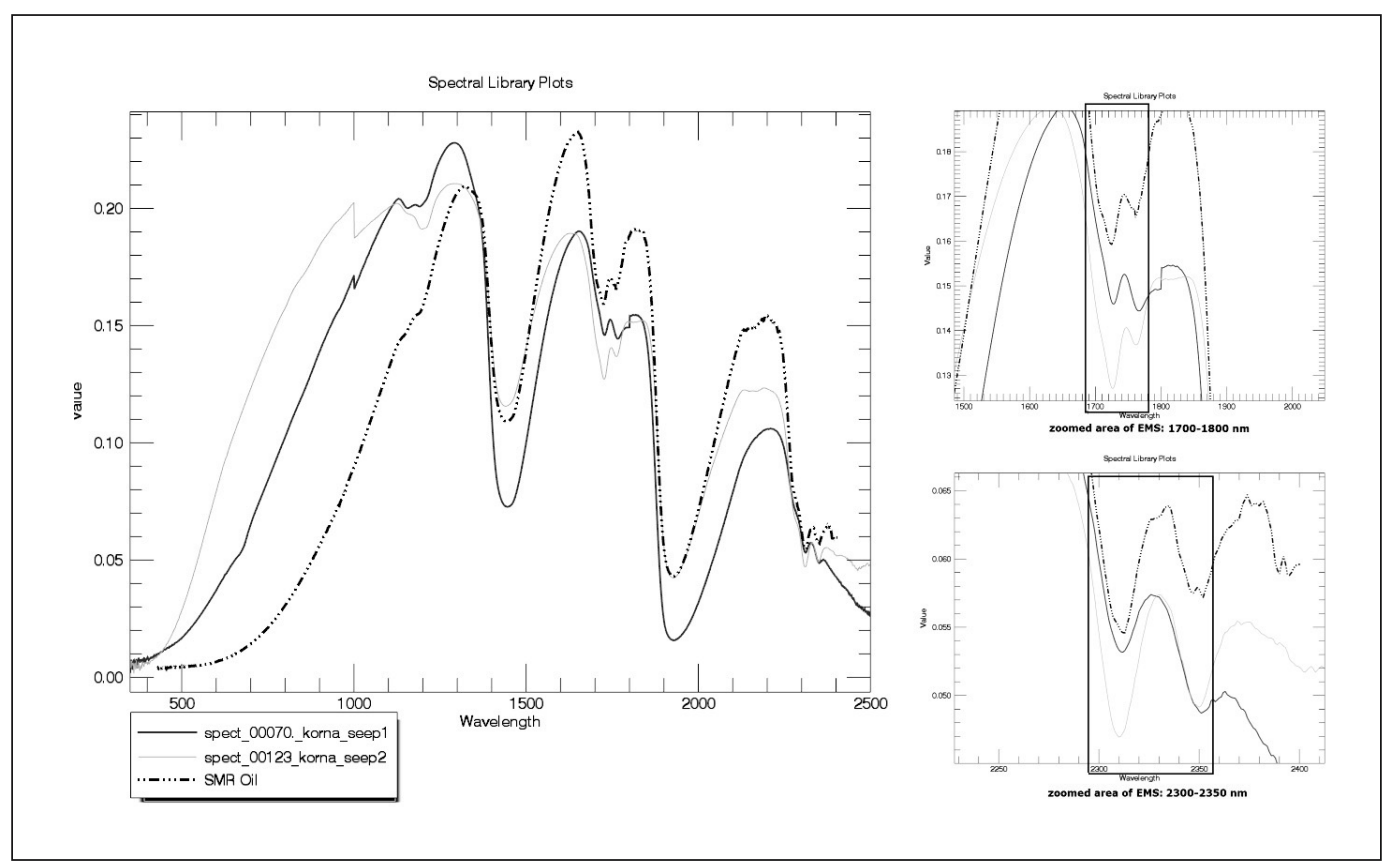

Fig. 3. Spectral library comparisons (oil seep) 
in-situ measurements of Korn̆a natural oil seepage. The sample acquired from the seep (no.70) matched mostly (score 1.29 from 2.00) the "SMR Oil" spectra taken in the lab from liquid oil sample from California. The spectra taken from the dead plant material and wood near Ojai seepage fitted (score 2.114 from 3.000) the spectra taken from the bare soil near Korňa hydrocarbon seepage. The results from matching methods proved that the building of spectral library for Korňa natural hydrocarbon seepage was successful.

\section{Spectra based classification discussion}

With spectral library data the methods using it on the input could be applied. In our study the SAM (Spectral Angle Mapper) and MDC (Minimum distance) classification were tested with the data ASTER from Korňa and Nesyt area and with available Hyperion data from the area south from Nesyt.

The past studies (Werff et al. 2007) showed results of successful application of both classifications using airborne hyperspectral data from the area of Ojai seepages. Up to now, our research efforts and use of the satellite data as the input to the spectra based classification did not show satisfactory results. We assume that the input satellite ASTER and Hyperion data need to be pre-processed, resampled and specifically prepared for this purpose. Then it seems to be appropriate to test the spaceborne data from the Ojai California. Further advances of our activities will be focused on these intentions.

\section{Computations of HD, HI, RE discussion}

The formulas of the indexes were prepared for the computations in ENVI software tool. The calculations of band ratios (indexes) were performed, the initial tests were carried also with the airborne data from Ojai seeps. Afterwards, the calculations of HD and HI were performed with Hyperion data in the Czech and Slovak area. Hyperion data input is the only satellite sensor which can be utilized for the HI and HD computations. The calculations of the indexes with the Hyperion (Nesyt-Gbely) data were performed. Until now the results of these calculations

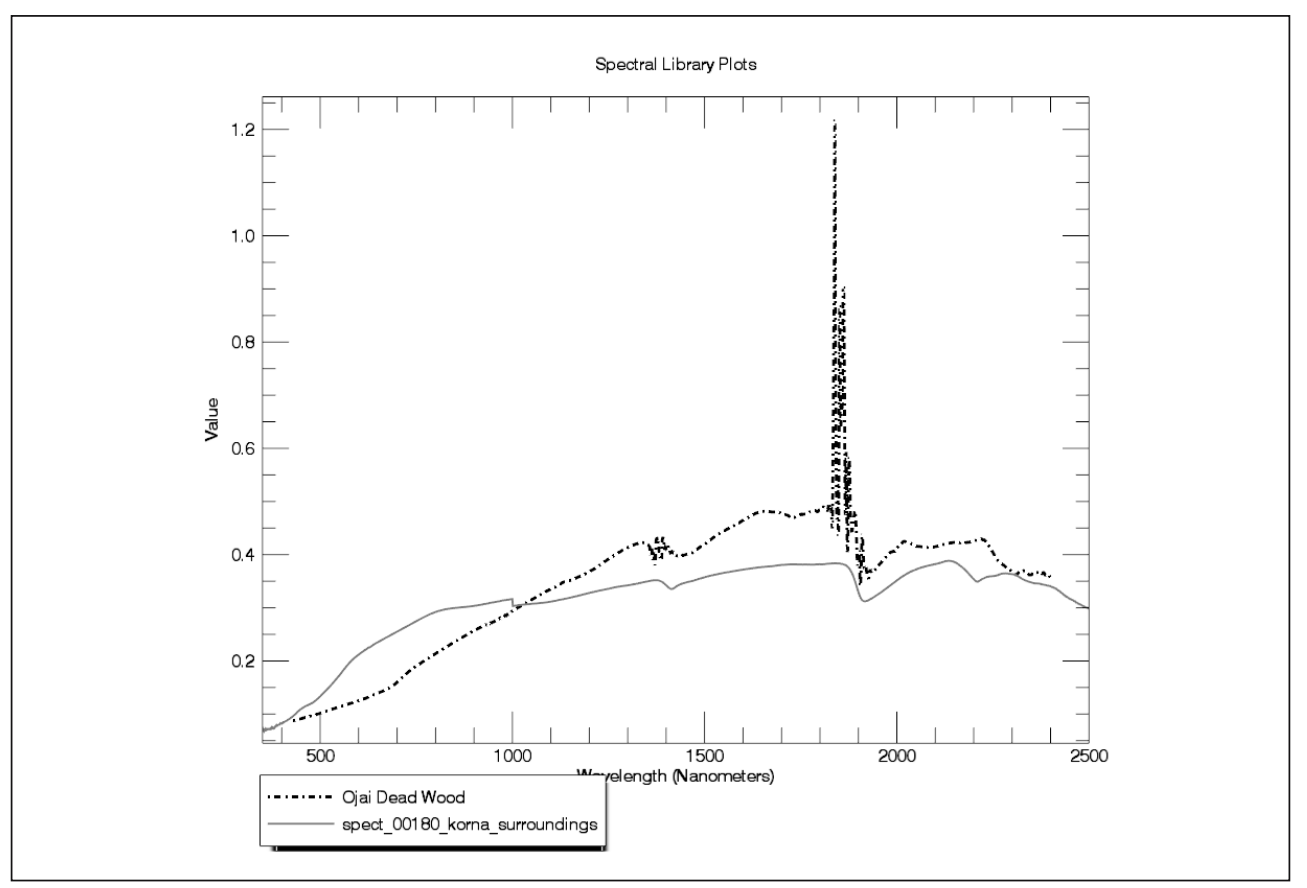

Fig. 4. Spectral library comparisons (oil seep surroundings)

Table 3. Results with spectral matching methods of spectral libraries

\begin{tabular}{|c|c|c|c|c|c|}
\hline \multirow{2}{*}{ Korňa SL } & Ojai SL & $\begin{array}{c}\text { Match } \\
\text { method }\end{array}$ & Dead wood & Tar Seep & \multicolumn{2}{|c|}{ Tar Road } & SMR Oil \\
\hline \multirow{3}{*}{ Oil seep } & SAM & 0.388 & 0.388 & 0.377 & 0.536 \\
\cline { 2 - 6 } & BE & 0.600 & 0.600 & 0.647 & 1.024 \\
\cline { 2 - 6 } & Score & 0.823 & 0.988 & 0.754 \\
\hline \multirow{2}{*}{$\begin{array}{c}\text { Oil seep } \\
\text { surroundings }\end{array}$} & SAM & $\mathbf{0 . 7 0 0}$ & 0.623 & 0.700 & 0.379 \\
\cline { 2 - 6 } & SFF & $\mathbf{0 . 4 9 4}$ & 0.507 & 0.494 & 0.550 \\
\cline { 2 - 7 } & SE & $\mathbf{0 . 9 2 0}$ & 0.932 & 0.920 & 0.777 \\
\hline
\end{tabular}


contain noise (sensor noise, striping effect of the sensor) due to EO-1 Hyperion data which are acquired from space. The target of our study is now to prepare the Hyperion data suitably, to study the first results of HD and HI computations and perform successful band ratios.

For calculating the shift in red-edge (RE) in the area of Nesyt and Korn̆a the preparation phase was done. The computation of normalized difference vegetation index (NDVI) to classify the vegetation and use it as a mask layer was successful. The calculations of shift in RE with Ali and ASTER data from the area of Korňa were computed with other available formulas, e.g. Lichtenthaler Indice (Noomen 2007). The essential step now is to deeply analyze the results and to study the shifts depending on present vegetation stressed by occurring hydrocarbon seeps.

In general, the past research focused on studying the oil seepages using airborne Earth Observation data. In ongoing study the aim is to try to analyze the satellite EO data which means the data acquired at approx. altitude of $700 \mathrm{~km}$. Minor part of the research and practical technical studies already performed are using only the spaceborne data. One of the crucial points is lack of hyperspectral spaceborne data suitable for the hydrocarbon detection.

The methods utilized for the purpose of this study showed that it is necessary to have high quality input data (as in the past studies for selected approaches only airborne data were utilized). This gap is under consideration and we are continuing our analyses. The important outcome of the presented study is successful building of the spectral library. To handle the successful computation of hydrocarbon indexes needed is to correctly pre-process and prepare Hyperion satellite data. For performing the spectra based classification the built spectral library is suitable to use.

\section{Conclusions and further prospect}

The Earth observation offers the opportunity to use the stateof-the-art measurement techniques in the geological sciences and in the environmental engineering and monitoring. Using the satellites and progress in their data processing enables to investigate the hydrocarbons in the innovative way and support the contribution to the paramount importance of the protection of our environment against the pollution. Using the satellites and progress in their data processing enables one to investigate the hydrocarbons in the innovative way and support the contribution to the paramount importance of the protection of our environment against the pollution.

The results showed the successful building of the spectral library which was compared with standard library based on Ojai California hydrocarbon seeps. The enrichment of the set of input data with field in-situ survey data from particular hydrocarbon seeps sites allows to better understand the spectral characteristics and to broaden the generality of the method. Then, during the study were selected 2 types of methods which can be applied for the satellite data from Korňa and Nesyt area of interest (calculations of indexes and spectral based classifications). The important criterion for both types of approaches is the quality and preparation of input satellite data. It is not sufficient to build the spectral library, to test the algorithms in the area where the seepage is known (Korňa). The further research advancements and activities are focused only on Nesyt area where the data on ancient drilling activities (map of oil wells), data on ground water contaminations as well as the geophysical ground penetrating radar measurements are available.

The practical application in our countries is not only in the field of contaminations due to badly plugged and abandoned oil wells but also for detection and mapping of the areas which were formerly impacted by Soviet army and contaminated by petrol products. The practical outcome of the study is possible integration of innovative methods with procedures for hydrocarbon exploration activities. The application field lies in the detection of possible occurrences of oil contaminations in the vicinity of insufficiently remediated boreholes and wells, in the observation and analysis of hydrocarbon seepages, and it also contributes to the problem of detection and remediation of old ecological hazards in the areas of the Czech Republic and Slovakia.

\section{Acknowledgements}

This article was written in connection with project Institute of clean technologies for mining and utilization of raw materials for energy use - Sustainability program. Identification code: LO1406. Project is supported by the National Programme for Sustainability I (2013-2020) financed by the state budget of the Czech Republic.

The authors are very thankful to the Faculty of Geo-Information Science and Earth Observation at University of Twente for providing the support, and also the field and airborne data from the area of Santa Barbara California, U.S. The radiometer Cropscan was loaned from Institute of Landscape Ecology, Slovak Academy of Sciences and authors are also very thankful to Slovak colleagues.

\section{References}

Abrams, M.A., Segall, M.P. \& Burtell, S.G. (2001). Best practices for detecting, identifying and characterizing near-surface migration of hydrocarbons within marine sediments, Offshore Technology Conference, 2001.

Beal, D. \& Eamon, M. (2009). Preliminary results of testing and a proposal for radiometric error correction using dynamic, parabolic linear transformations of "Stepped" Data (PCORRECT. EXE), Analytical Spectral Devices, Inc.

Bednaříková, J. \& Thon, A. (1984). Oil industry in the Czechoslovakia, MND, Nafta Gbely. Hodonín Czechoslovakia,1984. (in Czech)

Bentz, F.P. (1975). Landsat Data Contribution to Hydrocarbon Exploration in Foreign Regions, Proceedings of the First Annual William T. Pecora Memorial Symposium, Sioux Falls, South Dakota.

Carpathian Resource Limited ABN 30080279 703, Annual Report, (http://www.carpathian.com.au (30.06.2014)).

Dawson, T.P. \& Curran, P.J. (1998). A new technique for interpolating the reflectance red edge position, International Journal of Remote Sensing, 19, pp. 2113-2139.

Ellis, J.M., Davis, H.H. \& Zamudio, J.A. (2001). Exploring for onshore oil seeps with hyperspectral imaging, Oil\&Gas Journal, (http:// www.ogj.com/articles/print/volume-99/issue-37/special-report/ exploring-for-onshore-oil-seeps-with-hyperspectral-imaging.html (09.01.2017)).

Exelis Visual Information Solutions. 2010. Using ENVI. Boulder, Colorado, (https://www.exelisvis.com/docs/routines-136.html $(30.06 .2014))$. 
Horing, B. \& Kühn, F. (2001). HyMap hyperspectral remote sensing to detect hydrocarbons, International Journal of Remote Sensing, 22, pp. 1413-1422.

Khan, S.D. \& Jacobson, S. (2008). Remote sensing and geochemistry for detecting hydrocarbon microseepages, Geological Society of America Bulletin, 120 (1-2), pp. 96-105.

Kühn, F., Oppermann, K. \& Horig, B. (2004). Hydrocarbon Index - an algorithm for hyperspectral detection of hydrocarbons, International Journal of Remote Sensing, 25, pp. 2467-2473.

Milička, J. \& Macek, J. (2012). Historical and geochemical outlines of the oil-gas seepage near Turzovka town; Flysch belt, NW Slovakia, Acta Geologica Slovaca, 4 (1), pp. 7-13. (in Slovak)

Noomen, M.F. (2007). Hyperspectral reflectance of vegetation affected by underground hydrocarbon gas seepage, $P h D$. Thesis - ITC, University Twente, Enschede.

Noomen, M.F., Skidmore, A.K., van der Meer, F.D., Smith, K.L., Steven, M.D. \& Colls, J.J. (2004). The influence of gas pipeline leakage on plant development and reflectance, Asian Conference of Remote Sensing, Chiang Mai, Thailand, 2004.

Qingjiu, T., Yi, L. \& Lei, Z. (1992). A remote sensing basic study on the relation between spectral properties $(0.40-1.10 \mathrm{um})$ of the oil and gas microseepage in East Hebei Province, Proceedings of the Asian Conference on Remote Sensing, $13^{\text {th }}$ Asian conference, Remote Sensing, 1992.

Gluyas, J., Selley, R.C., Cocks, R.M. \& Plimer, M. (2005). Encyclopedia of Geology (Petroleum Geology), Elsevier, Oxford UK 2005.

Rubio, V. (2002). Correlation of the onshore hydrocarbon seepages with the geo-structural characterization in the Venura Basin, Santa Barbara area, California, PhD. thesis - ITC, University Twente, Enschede.

Short, N. (1998). Finding Oil and Gas in Oklahoma, The Remote Sensing Tutorial (An Online Handbook). Code 935, Goddard Space Flight Center, NASA (http://fas.org/irp/imint/docs/rst/ Sect5/Sect5_5.html (1.08.2014)).

Smejkalová, E. \& Bujok, P. (2012). Remote sensing methods in the identification of oil contaminations, GeoScience Engineering, 58, pp. 24-33 ISSN, DOI: 10.2478/v10205-011-0010-6.

Van der Werff, H.M.A., Noomen, M.F., Van der Meijde, M. \& Van der Meer, F.D. (2007). Remote sensing of omshore hydrocarbon seepage: problems and solutions, Geological Society, London, Special Publications, 283, pp. 125-133. 